\title{
Neuroectodermal tumours in the cerebellum in two sisters
}

\author{
M Y F A N W THOMAS, ${ }^{1}$ J. HUME A DAMS, A N DAVID DOYLE \\ From the University Department of Neuropathology, Institute of Neurological Sciences, Southern \\ General Hospital, Glasgow, Scotland
}

SUMMARY Two sisters, one 5 years and the other 2 years old, with intrinsic tumours of the cerebellum are reported. One of the tumours was interpreted as being a ganglioneuroma with neuroblastomatous change. The other was a desmoplastic medulloblastoma.

Tumours of neuroectodermal origin in siblings are very uncommon. So also are malignant cerebellar tumours with a ganglioneuromatous element. Both events occurred in the sisters reported briefly in the present paper.

\section{Case reports}

CASE 1

$\mathrm{JMcP}$ (N25308) was born in 1962 and progressed normally until February 1967 when she was admitted to hospital with a four day history of headache, vomiting, and intermittent drowsiness. No abnormal neurological signs were elicited apart from mild hypotonia. Lumbar CSF was clear and contained 2 mononuclear cells per $\mathrm{ml}$, protein $0.5 \mathrm{~g} / 1$, and $4.2 \mathrm{mmol} / 1(76 \mathrm{mg} / \mathrm{dl})$ of sugar. The pressure was not recorded. The patient was rehydrated and discharged home four days later asymptomatic. Over the next few days, however, her symptoms recurred and worsened, and she developed anorexia and enuresis. On readmission to hospital she was found to have truncal ataxia with a tendency to stagger to the left, hypotonic limbs, and papilloedema. Transfer to the Institute of Neurological Sciences was arranged where an iophendylate (Myodil) ventriculogram confirmed the clinical impression of a left cerebellar tumour. On 6 March, Mr J. Sloan Robertson excised what appeared to be a well-circumscribed tumour high up in the left cerebellar hemisphere and attached to the dura mater. The patient's postoperative condition was good. Over the next few weeks she

\footnotetext{
${ }^{1}$ Present address: University Department of Neurology, Institute of Neurological Sciences, Southern General Hospital, Glasgow.

Accepted 24 March 1977
}

received a course of radiotherapy to the neuraxis. She remained apathetic, however, and throughout June and July slept more and more frequently and continually refused food. She diad on 21 August, some six months after the onset of her illness. Permission for postmortem examination was not obtained.

Histology (K67091)

Several pieces of firm white tissue were submitted for examination. The largest specimen measured some $60 \times 35 \times 10 \mathrm{~mm}$, while a second specimen contained a fairly discrete firm white nodule measuring $20 \times 15 \times 5 \mathrm{~mm}$. Histological examination showed two distinct types of tissue. Part of the firm white nodule was of low cellularity and contained many large cells, some of which were binucleate or multinucleate (Fig. 1 and 2). The

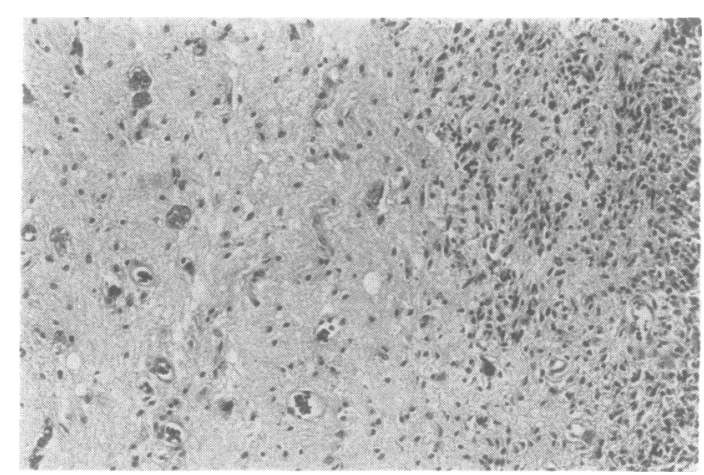

Fig. 1 Case 1. Section of tumour showing ganglioneuroma of low cellularity on left and fairly rapid transition to highly cellular tumour on right. Haematoxylin and eosin, $\times 6$. 


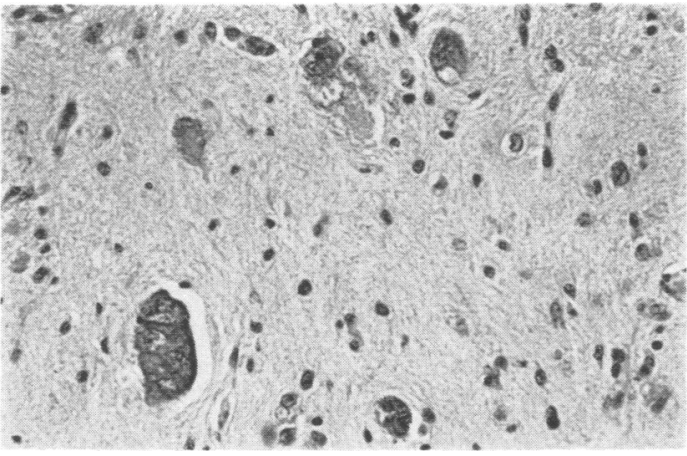

Fig. 2 Case 1. Ganglioneuromatous part of tumour. Note bizarre ganglion cells, low cellularity, and absence of tumour astrocytes. $H$ and $E \times 150$.

nuclei were large and vesicular and contained prominent nucleoli. Within the cytoplasm of most of these cells Nissl granules and neurofibrils were identifiable in appropriately stained sections. Among these cells, which were clearly ganglionic in type, there was a dense plexus of axis cylinders (Fig. 3). There were a few glial fibrils within this part of the tumour but no obvious tumour astrocytes. There was also a scanty fibrovascular stroma. On one side of this nodule there was a fairly sharp transition to densely cellular tumour (Fig. 1) which was similar in appearance to all of the other pieces of tissue submitted. The cells were small, round or oval, and had scanty cytoplasm (Fig. 4). Rosettes were not seen. The nuclei had well-developed nuclear membranes and contained many small chromatin dots but nucleoli were not identified. Mitotic figures were frequent. Among these cells there were numerous delicate axons (Fig. 5), but glial fibrils were not seen and there

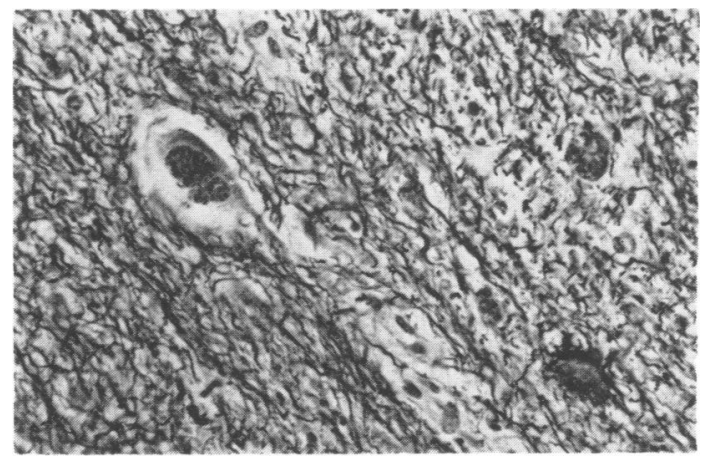

Fig. 3 Case 1. Ganglioneuromatous part of tumour. There is a dense plexus of axons between the ganglionic tumour cells. Palmgren, $\times 250$.

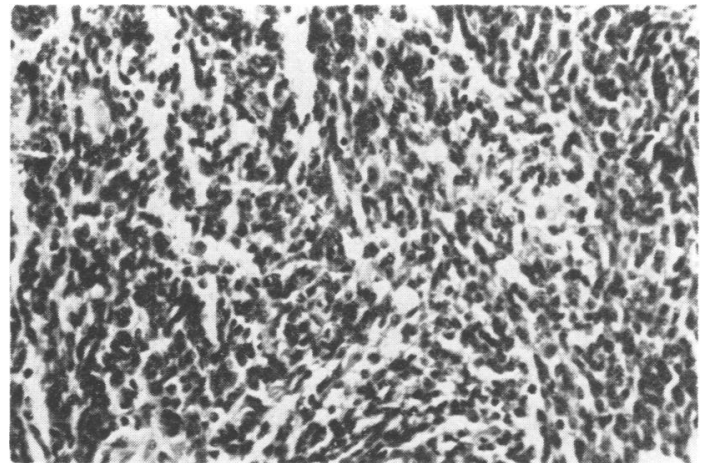

Fig. 4 Case 1. Neuroblastomatous part of tumour. This is composed of sheets of small dark cells with no specific identifying histological features. $H$ and $E$, $\times 150$.

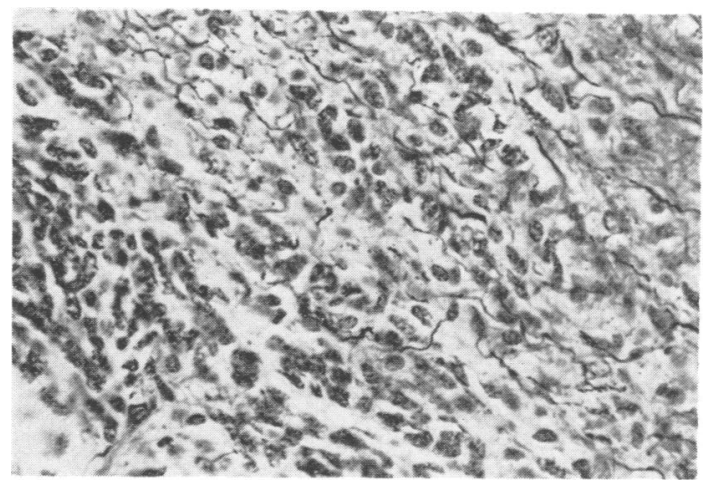

Fig. 5 Case 1. Neuroblastomatous part of tumour. Axons are conspicuous. Palmgren, $\times 200$.

was only scanty collagen and reticulin in relation to vessels.

Because of the network of axons in the highly cellular part of the tumour, mixed ganglioneuroma and neuroblastoma seemed to be the most appropriate diagnosis.

CASE 2

MMcP (803264) was born in February 1969. Early development was normal apart from delayed and unsteady walking, and she was never able to walk more than a few steps on her own. Speech, however, developed normally. In April 1971 she had a right sided clonic seizure after which she was unable to walk by herself at all. One month later she had a further seizure and was admitted to hospital where truncal and symmetrical limb ataxia, hypotonia, and brisk tendon reflexes were noted. Radiographs of the skull showed starting of the sutures. She was then transferred to the 
Institute of Neurological Sciences where an iothalamate (Conray) ventriculogram followed by a posterior fossa exploration by Mr J. D. Miller on 31 May revealed a midline cerebellar tumour with extensive subpial infiltration over both hemispheres. Subtotal removal was undertaken. The patient's postoperative recovery was satisfactory and a course of radiotherapy to the neuraxis was given. Her condition, however, progressively deteriorated and she died on 29 November about seven months after the onset of her illness. Permission for postmortem examination was not obtained.

\section{Histology (N71167)}

Several pieces of firm white tissue, the largest measuring some $40 \times 20 \times 10 \mathrm{~mm}$, were available for examination. Histological examination revealed a highly cellular tumour composed partly of sheets of small cells with hyperchromatic, slightly elongated nuclei, distinct 'pale islands' of slightly larger cells (Fig. 6) and narrow cords of

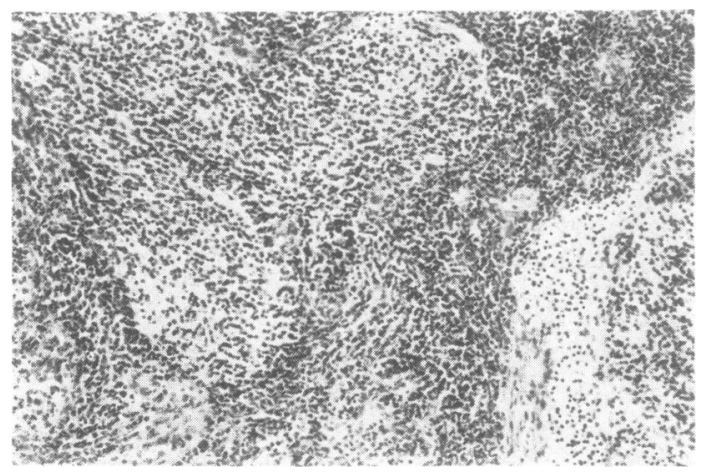

Fig. 6 Case 2. Tumour is composed of sheets of small dark cells and 'pale islands'. $H$ and $E, X 75$.

tumour cells running in parallel lines. Mitotic figures were numerous. Throughout the highly cellular areas and between the parallel cords of cells there was abundant collagen and reticulin. There was, however, a remarkable absence of reticulin in the 'pale islands' (Fig. 7). The appearances were typical of a desmoplastic medulloblastoma (Rubinstein and Northfield, 1964).

\section{Discussion}

There are at least three reports of posterior fossa tumours in siblings in the literature. Leavitt (1928) describes a pair of identical twins both of whom died of cerebellar tumours at the ages of

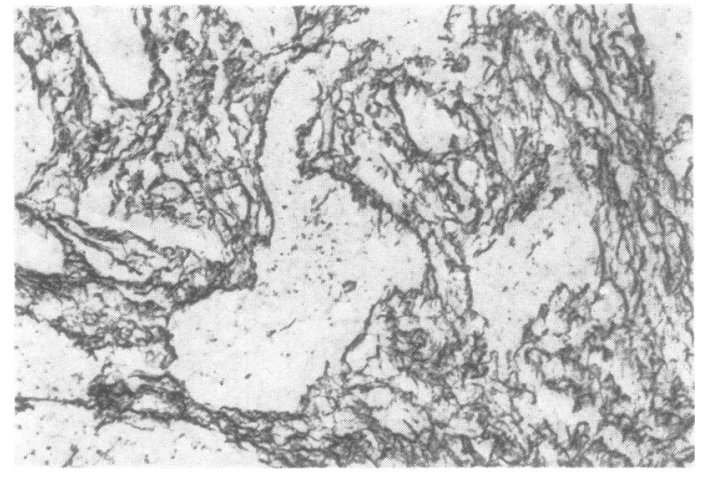

Fig. 7 Case 2. Reticulin is conspicuous in densely cellular areas but virtually absent from 'pale islands'. Reticulin, $\times 75$.

6 and 8 years respectively. The tumour in the first twin was a medulloblastoma but although the second twin had symptoms indicative of a cerebellar tumour a precise histological diagnosis was not obtained. Griepentrog and Pauly (1957) reported medulloblastomas in identical twins aged 8 weeks and 11 weeks respectively, and Bickerstaff et al. (1967) described the occurrence of medulloblastoma in two brothers in a family of five children at approximately the same age one year apart.

In each of the present cases medulloblastoma seemed to be the most probable diagnosis clinically and at operation. This diagnosis was confirmed in case 2 but the tumour in case 1 contained a firm and fairly well-defined nodule measuring up to $20 \mathrm{~mm}$ in diameter composed of highly aberrant and of ten multinucleate ganglion cells, and a dense plexus of axons. It is well recognised that tumour cells in a medulloblastoma may on occasion display varying degrees of ganglionic differentiation resulting in the appearance of atypical yet mature looking ganglion cells (Russell and Rubinstein, 1971), but differentiation of this type would not lead to the type of circumscribed nodule that was a conspicuous feature of this tumour. The appearances of this part of the tumour, therefore, were those of an intrinsic tumour containing bizarre ganglion cells. There is some controversy about the nomenclature of such tumours but in the absence of an abnormal glial element, ganglioneuroma would appear to be a more appropriate term for this part of the tumour than ganglioglioma (Russell and Rubinstein, 1971; Rubinstein, 1972). Such tumours tend to occur more frequently in children and young adults and a proportion seem to be more hamartomas than invasive tumours. Malignant change 
is, however, a well recognised complication in gangliogliomas and ganglioneuromas in the central nervous system but in gangliogliomas such changes are usually restricted to the gliogenic element (Russell and Rubinstein, 1971). Transitional forms between neuroblastoma and ganglioneuroma in the central nervous system have also been described (Hassin and Munch-Petersen, 1951; Russell and Rubinstein, 1971) but these usually consist of a mixture of cell elements ranging from highly primitive neuroblasts to well-differentiated ganglion cells (Rubinstein, 1972). The tumour found in case 1 would, therefore, appear to be an extreme rarity because of the fairly sharp transition from ganglioneuroma to a highly anaplastic neuroblastoma.

\section{References}

Bickerstaff, E. R., Connolly, R. C., and Woolf, A. L. (1967). Cerebellar medulloblastoma occurring in brothers. Acta Neuropathologica, 8, 104-107.

Griepentrog, F., and Pauly, H. (1957). Intra-und extrakranielle fruhmanifeste Medulloblastoma bei erbglichen Zwillingen. Zentralblatt für Neurochirurgie, 17, 129-140.

Hassin, G. B., and Munch-Petersen, C. J. (1951). Central neurogenic tumours (neuroblastoma and ganglioneuroma). A pathologic study of two cases. Journal of Neuropathology and Clinical Neurology, 1, 63-80.

Leavitt, F. H. (1928). Cerebellar tumours occurring in identical twins. Archives of Neurology and Psychiatry, 19, 617-622.

Rubinstein, L. J. (1972). Tumors of the Central Nervous System, pp. 158-163. Atlas of Tumor Pathology 2nd Series, Fasc. 6. Armed Forces Institute of Pathology: Washington DC.

Rubinstein, L. J., and Northfield, D. W. G. (1964). The medulloblastoma and the so-called 'arachnoidal cerebellar sarcoma'. Brain, 87, 379-412.

Russell, D. S., and Rubinstein, L. J. (1971). Pathology of Tumours of the Nervous System. 3rd ed. pp. 181207. Arnold: London. 